\title{
A IMPLICAÇÃO DO DIREITO NAS FORMAS DE VIDA E O JOGO DA LEGITIMAÇÃO: UMA ANÁLISE CRÍTICA DA DEFINIÇÃO JURÍDICA DE PESSOA
}

THE IMPLICATION OF LAW IN FORMS OF LIFE AND THE LEGITIMATION GAME: A CRITICAL ANALYSIS OF THE LEGAL DEFINITION OF PERSON

Gerson Faustino ROSA ${ }^{1}$

Murilo Henrique de BRIDA ${ }^{2}$

ISSUE DOI: $10.21207 / 1983.4225 .859$

\section{RESUMO}

O presente trabalho teve como objetivo fazer uma análise crítica da sociedade, sempre buscando desvendar o papel que o direito exerce nessa estrutura. Para tanto, foi realizado um estudo de natureza teórica. Em síntese, verificou-se que, o que aparenta ser uma sociedade equilibrada, pacificada e principalmente civilizada, na realidade não é, ou seja, analisando a fundo todo o meandro entre poder e

\footnotetext{
${ }^{1}$ Professor de Direito Penal nos cursos de pós-graduação e de graduação da Universidade Estadual de Maringá-PR (UEM); Professor de Direito Penal e coordenador da Pós-graduação em Ciências Penais na UNOESTE de Presidente Prudente-SP; Professor credenciado junto à Escola Superior de Educação em Direitos Humanos do Estado do Paraná (ESEDH); Professor de Direito Penal nos cursos de pósgraduação da Escola Superior da Advocacia (ESA), da UNIFAMMA, das Faculdades Maringá e da Faculdade Integrado de Campo Mourão-PR; Pesquisador do CNPq, com experiência na área do Direito, com ênfase em Direito Penal e Política Criminal, atuando principalmente nos seguintes temas: expansão e modernização do Direito Penal, parte geral, parte especial do Código Penal brasileiro e terrorismo. Doutorando em Direito pela Faculdade de Direito de São Paulo-SP (FADISP), Mestre em Ciências Jurídicas pelo Centro Universitário de Maringá-PR (2014), pós-graduado em Ciências Penais pela Universidade Estadual de Maringá - PR (2011), pós-graduado em Direito Penal e Processual Penal pela Universidade Gama Filho - RJ (2008), graduado em Direito pela Associação Educacional Toledo de Presidente Prudente - SP (2007). http://lattes.cnpq.br/520825984128359

${ }^{2}$ Graduado em Direito pela Universidade Estadual de Maringá.
} 
direito, bem como considerando todas as desigualdades e as relações de dominação ínsitas na sociedade contemporânea, observamos que, na verdade, vivemos em tempos atrozes, materializadas por sociedades desequilibradas que utilizam o ser humano como um meio às práticas econômicas e não como um fim em si mesmo. Nesta senda, a utilização do Direito Penal para subjugar a condição humana se torna evidente.

Palavras-chave: Legitimação Jurídica; Sociedade Incivilizada; Coisificação Humana.

\begin{abstract}
The current article had as purpose making a critical view of the society, always looking forward uncover the function that the Law exercises in this estructure. Therefore, was made a theoretical study. In summary, it was verified that what it looks like to be a balanced society, pacified and mainly civilized, actually it is not, that is, analyzing deeply all the relation between the Power and the Law, as well considering all the inequalities and the relation of domination inserted in the contemporary society, we can notice that, indeed, we live atrocious times, materialized by off-balance societies that use the human being as an implement for the economics practices and not as a purpose in yourself. Accordingly, the application of the criminal law to subjugate the human condition becomes evident.
\end{abstract}

Keywords: purpose that Law exercises; uncivilized society; human being as an implement.

\title{
INTRODUÇÃO
}

Nenhuma época acumulou, como a nossa, tantos conhecimentos e tão diversos sobre o homem, nenhuma conseguiu apresentar esses conhecimentos de maneira que nos atingisse tanto, nenhuma tornou esses conhecimentos tão prontos e facilmente acessíveis, porém nenhuma época soube menos sobre o que é o homem; a nenhuma ele pareceu tão misterioso ${ }^{3}$.

Nessa perspectiva, atualmente o homem deixa de existir para, pura e simplesmente, viver ou no mais assertivo sentido, apenas sobreviver. Conforme a figura do homo sacer exposta no livro de Giorgio Agamben ${ }^{4}$, há uma simbiose entre a vida nua e a vida politizada, assim o indivíduo deixa de lado a sua autonomia de ser, para se tornar um instrumento para fins estatais, reduzindo-se à condição de mera engrenagem dessa máquina sistemática, ao qual serve para colocar em prática a vontade do poder, mais precisamente de quem está no poder. Assim, aquela existência consistente no exercício de um ato de liberdade, quando não se produz e se reflete na prática, reduz o nosso ser ao estado de coisa.

Vive-se um instante da história em que as relações entre sujeito e Estado são técnicas e não éticas, onde se observa um vício macroscópico

\footnotetext{
${ }^{3}$ HEIDEGGER, M. Kant y el problema de la metafísica. Santiago do Chile: Editorial Fondo de Cultura, 1954, p.41.

${ }^{4}$ AGAMBEN, Giorgio. Homo Sacer: O Poder Soberano e a Vida Nua I. 2. ed. Belo Horizonte: Ufmg, 2014.
} 
no homem moderno, que explora o seu desejo de realização pautada unicamente na satisfação das necessidades econômicas, necessidades essas construídas pela própria sociedade. Consequentemente, a sociedade do consumo massificado revela-se por um amontoado de seres individuais manipulados e uniformizados que não fruem de liberdade e autonomia, sendo definidos como verdadeiros homo economics, algo que é fruto do liberalismo exacerbado e da subjetivação ética.

Nesta senda, sob a égide da isonomia formal, o social assume uma universalização que equaliza os integrantes da comunidade, nas relações econômicas, mantendo-os presos na teia econômica. ${ }^{5}$

Segundo Alessandro Zenni, esse ser massificado é amorfo, não possui personalidade e se mostra indigno da verdadeira essência do homem, de modo que "O transformador da natureza (homem) passou a ser a presa de sua estrutura"6.

Ademais, tornando o ser amorfo, destituído de autonomia e de senso crítico, o Estado monopoliza a violência como instrumento de manutenção e coesão social, assegurando a exclusão e a consequente desumanização daqueles considerados como violadores da ordem e do status quo. Tais indivíduos são vistos como verdadeiros homo sacers contemporâneos, que são lançados nas "masmorras" que costumamos chamar de penitenciárias e lá são esquecidos.

Cumpre salientar que, este mesmo Estado que se apropria da condição de ser humano para suas práticas biopolíticas, é um ente fortemente marcado por antinomias. Isto porque, a despeito da existência de vasta enciclopédia de direitos individuais, classificados como sagrado e garantidos constitucionalmente, observa-se concomitantemente que o indivíduo é um ser "matável", sem importância, tornando-se apenas mais uma manchete nos diários. Assim, o indivíduo encontra-se em uma zona simbólica, vivendo entre a teoria dos direitos humanos e a realidade da instrumentalização do ser.

Nesta senda, a vida que com as declarações dos direitos tinha sido investida como tal do princípio do soberano popular, torna-se agora ela mesma o local de uma decisão soberana.

\footnotetext{
${ }_{5}^{5}$ LIMA VAZ, Henrique Cláudio. Escritos de Filosofia: introdução à ética. São Paulo: Loyola. 1988, p. 362.

${ }^{6}$ ZENNI, Alessandro Severino Valler ; FELIX, D. V. . Educação para construção de dignidade: tarefa eminente do direito. Revista Jurídica CESUMAR. Mestrado , v. 11, 2011, p.28.
} 
Dessa forma, se faz necessário estudar e demonstrar, contrariamente ao que a maioria suscita, que os indivíduos não são verdadeiramente autônomos e dotados de liberdade, mas são indivíduos alienados socialmente frente ao sistema liberal. Não há mais um pensamento individual voltado à análise do $e u$, mas sim, conforme Freud assegura, o que existe é uma psicologia de massas $^{7}$, marcado pela destituição do pensamento individual/autônomo em prol de um fictício pensamento comunitário, na qual o direito exerce enorme influência em sua manutenção, conservando assim as bases do poder soberano.

Para tanto, dentre o rol de matérias jurídicas, o direito penal demonstra, de maneira totalmente evidente, a subjetivação de valores, relativização de garantias e consequente apropriação do ser humano, criando verdadeiras bio-políticas de segurança pública.

Com o intuito de lograr êxito no objetivo intentado, este trabalho foi subdividido em quatro partes. Na primeira parte, é demonstrado a concepção de ser humano e seu lugar na sociedade ao longo da história, fazendo raras considerações sobre o papel do direito como matéria autônoma, uma vez que a criação desta como matéria se deu a partir de Século XI. Na segunda parte, é feito uma análise crítica da sociedade contemporânea e o quanto o Direito contribui para sua manutenção, fazendo-se observações mais detalhada de fatos que contribuem na instrumentalização do homem, tornando-o um mero meio ao fins econômicos do Estado. $\mathrm{Na}$ terceira parte, problematiza-se a constitucionalização dos direitos humanos. Por fim, na quarta e última parte, há uma análise crítica do papel desempenhado pelo Direito Penal em defesa da manutenção do status quo e sua contribuição na banalização da condição de ser humano.

\section{A CONCEPÇÃO DE SER HUMANO AO LONGO DA HISTÓRIA}

\section{$2.1 \quad$ ANTIGUIDADE}

A concepção de ser humano, solidificado na expressão dignidade da pessoa humana, é conceito que não existiu entre gregos e romanos. Na antiguidade, havia apenas uma preocupação com a liberdade e com o exercício da cidadania, de modo que aqueles que nasciam nas cidades e que

\footnotetext{
${ }^{7}$ FREUD, Sigmund.Psicologia das Massas e Análise do Eu. Editora L\&PM Pocket. 2013.
} 
podiam estar nas praças das cidades gregas (ágora) ou na res pública em Roma, eram dotados de liberdade participativa e política - exercício da politeia - ampliando-se, assim, a capacidade léxica e discursiva do sapiens.

Não se olvide, entretanto, que, o mundo antigo concebeu o mundo como cosmos, ordem perfeita, dentro da qual o homem é parte desse contexto da natureza, sendo pré-concebido conceitos como real e verdadeiro. Restava ao homem deflagrar suas capacidades especulativas e práticas presentes na razão, ampliando suas potências convertidas em ato, isto é, physis como movimento, telus como finalidade.

A felicidade plena, ao alvedrio de Aristóteles, atinge-se como finalidade na expansão do cognitivo e no encontro com a verdade. Notadamente, a dimensão política no campo prático traduz-se como perfeição ao bem e consequente prática excelente por natureza. Aqui se faz necessário ressaltar a magnitude e a grandeza com que o termo ética se apresenta, sendo concebida como qualidade que o ser humano utiliza para alcançar sua plenitude como ser integrante dos cosmos, isto é, é o instrumento/meio para se alcançar a plenitude do ser.

Não obstante a enorme discussão no campo da ética, na antiguidade é fixado um modelo de sociedade estamental, onde havia a categoria dos incluídos e dos excluídos socialmente, tratando-se dos primeiros como verdadeiros cidadãos passíveis de exercitarem em sua plenitude todos os direitos - como a liberdade - sendo agraciados com a garantia de personalidade jurídica, isto é, a capacidade de contrair direito e obrigações; ao passo que os excluídos caminhavam a margem de proteção jurídica, principalmente porque não eram considerados seres-humanos/pessoas. Entre os excluídos figuravam as mulheres, os escravos, estrangeiros e os animais, todos tratados como res, verdadeiros objetos destituídos de capacidade jurídica.

Assim, a liberdade entre os antigos é caracterizada por uma liberdade participativa, isto é, os indivíduos considerados cidadãos possuíam liberdade para discorrer sobre os assuntos públicos, incrementos do bem comum. Tal liberdade era exercida na ágora, um espaço público onde somente cidadãos das poles se reuniam.

$\mathrm{Na}$ esfera do privado encontra-se o lar, dentro do qual vigora tirania, totalmente contrária aos valores apregoados na ágora. O pater determina e os demais acatam, e mesmo o chefe da família vive dependente de outrem para satisfação de necessidades, fixando-se assim o governo doméstico numa relação marcada por causalidade, a qual o corpo - resto de 
vida - há de ser controlado e moderado nos instintos, paixões e volúpias. Exatamente por submeter-se ao corpóreo e tentar modelá-lo, o privado não reserva liberdade e nada interessa aos olhos da comunidade.

Para tanto, basta recordar que a união entre homem e mulher, no espaço privado, se fixava em nome da procriação e sobrevivência, tal qual o poder exercido pelo senhor em relação ao escravo, alistando necessidade e sobrevivência.

Essa "coisificação" de determinada "classe" de seres humanos era explicado e aceito como algo natural pois, como dito anteriormente, para eles todo o universo estaria perfeitamente ordenado e tudo e todos alcançam sua plenitude como seres humanos quando obedecem e imitam essa ordem dada pela natureza, devendo portanto se engajar a esta ordem.

A ordenação espelhada no cosmos também registrava uma hierarquia de valores e a estimativa humana a estes bens compunha o caminho do atingimento ontológico dos fins do ser.

Insta ressaltar por fim que, a esta época, surgiram as bases de um jusnaturalismo clássico cujas normas humanas eram decifradas pela própria natureza. Assim sendo, para o homem internalizar esta ordem do cosmos, era necessária muita filosofia especulativa, motivo pelo qual o direito se confundia a política e a valores.

\subsection{IDADE MÉDIA}

Com relação a idade média, não obstante a sociedade estamental composta de incluídos e excluídos continuasse amplamente enraizado em sua estrutura, houve uma renovação fortemente idealizada pelo cristianismo por meio de seus filósofos Agostinho e Tomás de Aquino, que criaram conceitos até então desconhecidos pela sociedade.

De Agostinho se vislumbra aguda preocupação com a liberdade humana, e a partir dele se pode afirmar que houve prenúncio de deslocamento do problema da liberdade, que até então era circunscrito a categoria ou status do cidadão, para um mergulho metafísico, onde no âmago do ser se pode senti-la como potência apta a trazer felicidade ao indivíduo.

Ademais, a liberdade se dissocia do conceito de autonomia para discorrer sobre assuntos públicos - como um mero poder inerente aos cidadãos - e passa a figurar como verdadeira liberdade de escolha, materializada no conceito de livre arbítrio - conceito este fortemente propagado na idade média. 
De Tomás de Aquino surgem contribuições marcantes para toda a humanidade. Aquino defendeu que o homem é um ser social e não um animal político - conceito este propagado por Aristóteles. Na guinada formulada por Tomás de Aquino, a concepção de sociedade, fenômeno natural ontológico da espécie humana, tem como sucedâneo uma causa amoris.

As relações do espaço privado, que até então eram marcadas por uma tirania, mudam radicalmente na medida em que aqueles que eram considerados res passam a ser vistos como seres sociais e essa agregação se forma por causa do amor que nutrimos por eles, pois o sociável está presente ontologicamente no ser.

Ademais, o cristianismo escandaliza a cultura grega, uma vez que sugere o perdão como mandamento peculiar, ao mesmo tempo em que inclui, sob sua lei, todos os excluídos sociais até então desqualificados como ser.

O amor de Deus passa a figurar como o centro de nossa existência, e tratando de situação que reclama da natureza humana demasiado esforço porque não se sabe, seguramente, quais ações aplicadas são garantia dessa devoção, de modo que a Eclésia - comunidade dos chamados - deveria construir um bem comum de relativa compreensão, permanentemente discutido que, a um só tempo, vai sendo tecido pelos seus integrantes e os vai tecendo em relação de implicação.

Isto posto, com a quebra de paradigmas até então aceitos pela sociedade, surgiu o conceito de dignidade da pessoa humana. Com efeito, na concepção tomista, a centelha da divindade plasma todo ser humano, de sorte que dignidade, enquanto atributo do homem, e característica ontológica de todo e cada um dos indivíduos, marca uma identidade de origem e destino que os tornam um em Cristo, constituindo-se imagem e semelhança deste.

Nesta senda, o indivíduo possui uma potência natural que, ao ser materializada, o torna digno. O meio para atingir a transcendência e dignidade é a práxis virtuosa, ou seja, ação livre - aqui a liberdade caminha junto com a dignidade da pessoa humana - focada ao bem comum, à ética e ao justo. Outrossim, a vida humana digna vai sendo forjada a partir de circunstâncias concretas na convivência diária urdida no exercício virtuoso.

Esta potência herdada da Causa Eficiente, cunhada de dignidade, permite desenvolvimento, evolução, e transforma o homem em pessoa, cunhando-o de um sentido de vida dinâmico e enobrecedor. 
Pico Della Miràndola, humanista do Renascimento italiano, resgata a filosofia aristotélica, enfatizando a existência da dignidade humana a partir do laivo de liberdade presente no agir e na escolha da direção, defendendo que:

A dignidade do homem está longe de ser algo dado ou acabado e mecanicamente fixo. Ela é mais uma conquista porque a natureza humana é perfectível. O homem se faz. Como está perfectibilidade está condicionada pela liberdade, é na dinâmica do processo de conquista de si e de autodignificação crescente que o homem precisa da Filosofia.[...] A liberdade não é meramente um "dom" dado por Deus ao homem, mas a capacidade de escolher dentre diversas possibilidades. Cada homem, ao decidir seu destino, decidirá também o que é. Poderá degenerar e se tornar semelhante aos animais ou regenerar-se e tornar-se como os anjos. Afastar-se ou aproximarem-se da perfeição, eis as possibilidades que estão diante do ser humano. ${ }^{8}$

Ocorre que, sucessivamente por obra de Dans Scoto e Guilherme de Occam, representantes franciscanos da igreja, a natureza humana enquanto teoria perde vigor, fundando-se a um só tempo paradigmas que deixaram marcas indeléveis na modernidade, máxime o nominalismo e o atomismo.

O Scotismo negou realidade aos conceitos, tratando-se de puras abstrações formais, flatus voicis, e de certa forma o abstrato do conceito não passou de um feixe de palavras vazias que recebe quaisquer conteúdos.

Já Guilherme de Occam, a partir do atomismo, enfatiza o indivíduo como a base da sociedade, abstraindo-lhe a realidade geradora de sua ontologia, tendo em vista que é por meio do individuo que tudo é criado expondo, assim, as bases para o individualismo e antropocentrismo.

De mais a mais, a natureza humana foi desprezada como potência de perfeição, como imagem do Criador, e com isso houve um declínio ético implícito, exigindo-se que a lei externa seja responsável pela modulação do comportamento humano.

O direito já não será consubstanciado pelo ético, mas, ao contrário, a lei externa imposta é que definirá o que é jurídico. Cumpre salientar que aqui o direito ganha contorno de ciência e passa a ser limitado àquelas normas impostas pelo Estado.

\footnotetext{
${ }^{8}$ PICO DELLA MIRANDOLA, Giovanni. Discurso sobre a dignidade do homem. Tradução e introdução de Maria de Lurdes Sirgado Ganho. Lisboa: Edições 70, 2001, p. 21.
} 
Nesta diapasão, o nominalismo figura como fonte de toda redução do sentido moderno de dignidade humana, como ainda permitiu a completa relativização dos valores, com possibilidades de que algo externo à natureza das coisas pudesse definir certo fenômeno, como ética, direito ou pessoa, delineando assim a própria natureza.

Por fim, insta ressaltar que, em meados do século XI surgiram as primeiras faculdades ocidentais que, dentre outras matérias, criaram o estudo do direito como uma matéria autônoma. Entretanto, os primeiros estudos se limitaram ao resgate de institutos romanos.

\section{A CRÍTICA A SOCIEDADE CONTEMPORÂNEA}

Sob forte inspiração nominalista e antropocentrista e com o objetivo de "racionalizar" a sociedade, marginalizando tudo aquilo que não é palpável/materializado, bem como enfatizando novos valores com o intuito de progresso da humanidade, mantendo-se a ordem e a segurança, almejando valores tais como o trabalho, a propriedade privada e a perspectiva lucrativa destes, a modernidade causou uma ruptura com os conceitos até então almejados.

A base e o fundamento da modernidade estão no modus operandi da cognição, a intrepidez do método científico em detrimento da substância, da essência e do ontológico.

As formas lógicas, implicadas no ato de conhecer, emancipam o ser racional de modo que a qualidade de sujeito pensante vai às raias do $e u$ transcendental e deságua na supressão do real pelo aparente e no consequente materialismo exacerbado.

Com a modernidade pautada na racionalidade, no materialismo e no subjetivismo, o indivíduo entra em uma enorme crise existencial, marcada por uma antinomia extrema em que são criados inúmeros direitos como liberdade enquanto gênero, dignidade da pessoa humana, isonomia, valores sociais do trabalho - um verdadeiro rol poético de direitos; e ao mesmo tempo o ser humano é marginalizado em seu sentido ontológico, considerado um meio para os fins do modelo que rege-se pelo capital, modelo este que é sustentado e mantido pelo próprio direito. 
Ademais, a sociedade contemporânea, fortemente marcada pela rigidez jurídica, se apropria da figura do homo sacer ${ }^{9}$ - indivíduo presente no direito romano que, segundo Giorgio Agamben, era legalmente excluído do direito e portanto sem relevância jurídica - qualificando-o atualmente ao status de bandidos e marginais, verdadeiros inimigos da "sociedade pacífica".

Assim, o Homem, que inicialmente cria o Estado com o intuito de facilitar a vida em "bando", a vida em comunidade, encontra-se ele mesmo abandonado pelo próprio Estado. Este ente criado pelo Homem desenvolveu-se de tal maneiro que atualmente há uma simbiose/associação entre o Estado e o próprio direito. Dessarte, aquele direito que outrora era visto como fundamento da própria natureza humana, agora é basicamente o fundamento do Estado soberano que, utilizando-se deste poderoso instrumento de coesão, cria zonas de anomias/exceção.

Nesta senda, a sociedade é marcada por fortes antinomias, dentre as quais aquela materializado pelo papel exercido pelo Direito, uma vez que, o mesmo meio que aparentemente cria mecanismos para "proteger" o indivíduo, paralelamente o discrimina, minorando-o, retirando sua autonomia e sua liberdade, garantido assim a manutenção do status quo social e a vontade daqueles que estão no poder, vontade esta que se confunde com a vontade do próprio Estado.

Para Zygmund Bauman, em seu livro "Modernidade Líquida", a modernidade é classificada em dois estágios. A modernidade sólida é o estágio inicial da modernidade, em que há um rompimento com as tradições que até então imperavam; tradições estas que bloqueavam o avanço e o progresso social, criando-se, assim, novos e aperfeiçoadas instituições duradouras, chamadas sólidas. Já a modernidade líquida é o estágio em que vivemos atualmente, marcado pela volatilidade, pela flexibilização dos costumes, em que não há pressupostos confiáveis para se ater, sendo fortemente marcada pela individualização e subjetivismo, consequência da libertação do capital ${ }^{10}$.

Nesta senda, a tarefa de construir uma ordem nova e melhorada não figura hoje como objetivo a ser perseguido pelo Estado, ou seja, a modernidade líquida, muito embora precise, não reclama por mudanças marcantes em sua estrutura, uma vez que já alcançou seus objetivos.

\footnotetext{
${ }^{9}$ AGAMBEN, Giorgio. Homo Sacer: O Poder Soberano e a Vida Nua I. 2. ed. Belo Horizonte: Ufmg, 2014.

${ }^{10}$ BAUMAN, Zygmunt. Modernidade Liquida. Rio de Janeiro: Ed. Zahar, 2001.
} 
Assim, verifica-se a dificuldade para impor certas mudanças, já que, por se tratar de uma modernidade fluída, fugaz, dá-se a falsa impressão de liberdade para os indivíduos que a compõe.

Por conseguinte, tem-se que a modernidade que outrora defendia a mudança no intuito de progresso da humanidade, rompendo com a ordem e o valores até então vigentes, atualmente se enrijece e se "blinda" perante qualquer iniciativa de mudança, garantindo assim que a própria modernidade não sofra nenhuma alteração profunda em seu modus operandi.

Ademais, paralelamente ao monopólio do direito, o Estado insere, por meio dos meios de comunicação, uma falsa ideia de liberdade para população, que pensam que liberdade está associado única e exclusivamente ao consumo.

Zigmundo Bauman critica veementemente essas falsas percepções e valores apregoados pelo direito:

É a possibilidade de que o que se sente como liberdade não seja de fato liberdade [...] que vivendo na escravidão se sintam livres, e portanto não experimentam a necessidade de se libertarem [...] A obediências aos padrões tende a ser alcançada hoje em dia pela tentação e pela sedução e não mais pela coerção - e aparece sob o disfarce de livre arbítrio, em vez de revelar-se como força externa ${ }^{11}$.

Para desestimular a verdadeira liberdade, a sociedade vincula a plena liberdade a um sentimento de tristeza e agonia, prenunciando um medo paralisante dos riscos, dos fracassos e das consequências. Entretanto o que não dizem é que o que faz um acontecimento causar satisfação é sua própria produção, com responsabilidade substancial sobre seus próprios ombros.

Nessa linha, a liberdade para consumir é amplamente difundida tendo em vista que o consumo desenfreado é outro mecanismo que, aliado ao direito, retira o poder individual, uma vez que o consumo, em consonância com a sociedade massificada, embeacializa os indivíduos, domesticando-os, realocando suas principais preocupações e consequentemente dificultando ainda mais as mudanças significativas na sociedade atual. Assim, a liberdade de ter sobrepõe-se a liberdade de ser.

Tamanho é o medo da liberdade, que o Estado incuti, no modo de viver dos indivíduos, que atualmente cabe ao próprio Estado - sempre

\footnotetext{
${ }^{11}$ BAUMAN, Zygmunt. Modernidade Liquida. Rio de Janeiro: Ed. Zahar, 2001, p. 110.
} 
utilizando-se do direito - regulamentar todas as situações passíveis de conflito, normatizando e enrijecendo a margem de liberdade do comportamento humano.

Deve-se ter em mente, entretanto, que ao se falar em transformações, o principal agente dessas modificações estruturais é o ser pensante, dotado de uma reflexão crítica e de liberdade para mudar. Nesta senda, o consumismo retira preocupações significativas para uma mudança social e insere preocupações superficiais como, por exemplo: "o que devo comprar? Devo comprar o produto A ou B? O que é mais barato? Como vou ganhar mais dinheiro para conseguir estes produtos?".

Isto posto, como dito anteriormente, a sociedade contemporânea positiva inúmeros direitos, porém apenas o positivam de forma meramente poética, tendo em vista que o objetivo final da modernidade não é progredir, mas sim estagnar, permanecer no poder, proteger suas estruturas e petrificar o principal agente transformador, ou seja, o ser humano crítico. Para tanto, o Estado cria instrumentos para transferir o poder do indivíduo para o próprio Estado, fortalecendo-o com o intuito de manutenção do status quo. Neste cenário, o Estado monopoliza o direito por meio do ordenamento jurídico, utilizando-o como principal mecanismo e forte aliado para concentração de Poder nas mãos de poucos.

\section{A PESSOA E O CIDADÃO: UMA ANÁLISE CRÍTICA DA CONSTITUCIONALIZAÇÃO DOS DIREITOS HUMANOS}

Vive-se uma era de suposta expansão de direitos fundamentais que adquirem tais status ao serem constitucionalizados em um ordenamento jurídico soberano - mas ao mesmo tempo o humano nunca pareceu tão abstrato e ontologicamente vazio.

A constitucionalização de tais direitos - ditos fundamentais e inerentes à condição de ser humano - se deu principalmente por parte do pensamento filosófico contemporâneo que tem como base a reflexão sobre os direitos humanos, especificamente a relação entre indivíduo e Estado democrático. É o que se infere do livro de Habermas, Direito e Democracia: 
plantados na natureza humana. Dela brotam direitos fundamentais e inalienáveis, direitos legitimamente atribuíveis a todo homem em função de sua humanidade, prerrogativas éticas e jurídicas universais cuja validade se sobrepõe aos ordenamentos jurídico-políticos empíricos que, com efeito, teriam a função precípua justamente de assegurá-los e torná-los efetivos ${ }^{12}$.

Isto posto, os Estados soberanos contemporâneos, com o intuito de legitimação, nada puderam fazer se não constitucionalizar tais direitos inerente à condição de ser humano.

Assim, deveríamos estar vivenciando a era dos direitos sem precedentes na história humana. Ocorre que, o que temos hoje é uma vida exposta como tal a uma violência sem precedentes, mais precisamente nas formas mais profanas e banais, onde o ser humano se encontra totalmente despido de sua humanidade e de condições mínimas que garantam uma vida digna.

Isto porque, os Estados soberanos, paralelamente a constitucionalização de direitos humanos, também constitucionalizam certos institutos que podem relativizar aquilo que outrora foi preconizado como absoluto.

Hannah Arendt e Norberto Bobbio rejeitam a falsa crença de que a mera positivação jurídica dos direitos humanos nas Constituições dos Estados constitua razão e meio eficaz para a efetiva realização dos mesmos, dado que, aquele Ente que é responsável pela positivação de tais direitos é o mesmo ente que o relativiza em circunstâncias "excepcionais".

Neste cenário, não foram os direitos humanos que foram constitucionalizados, mas sim os direitos dos cidadãos. Para o Direito, cidadania qualifica os participantes da vida do Estado, sendo atributo das pessoas integradas na sociedade estatal, atributo político decorrente do direito de participar no governo e direito de ser ouvido pela representação política. Desse modo, o Estado não protege de fato os indivíduos que na qualidade de seres humanos merecem proteção por simplesmente existirem, mas tutelam tão somente aqueles que estão inseridos e possuem vínculo com o próprio Estado.

Ora, a despeito da teoria contratualista de Hobbes, deve-se formar um pensamento crítico no sentido de problematizar a própria legitima-

12 GIACOIA JUNIOR, Junior. Sobre direitos humanos na era biopolítica. Disponível em:http://www.scielo.br/scielo.php?script=sci_arttext\&pid=S0100-512X2008000200002. Acesso em: 20 de out. de 2018 , p. 3. 
ção dos Estados soberanos para definir "quem" e "o que" deve ser protegido pelo direito. Nesta senda, muito problemático se torna a relação Estado/indivíduo, já que, aqueles que criaram o Estado para gerir a vida em comunidade, agora se encontram submissos e a mercê das decisões deste ente.

\section{Nosso ordenamento jurídico pátrio, fundamentando sob a égide} da Constituição Federal de 1988, possui uma ampla gama de artigos que garantem, de fato, diversos direitos, limitando-os, porém, seu exercício à condição de cidadão. Senão vejamos a título de exemplo:

Art. $5^{\circ}$. Todos são iguais perante a lei, sem distinção de qualquer natureza, garantindo-se aos brasileiros e aos estrangeiros residentes no País a inviolabilidade do direito à vida, à liberdade, à igualdade, à segurança e à propriedade, nos termos seguintes: (...)

LXXIII - qualquer cidadão é parte legítima para propor ação popular que vise a anular ato lesivo ao patrimônio público ou de entidade de que o Estado participe, à moralidade administrativa, ao meio ambiente e ao patrimônio histórico e cultural, ficando o autor, salvo comprovada má-fé, isento de custas judiciais e do ônus da sucumbência; (...)

Art. 61. A iniciativa das leis complementares e ordinárias cabe a qualquer membro ou Comissão da Câmara dos Deputados, do Senado Federal ou do Congresso Nacional, ao Presidente da República, ao Supremo Tribunal Federal, aos Tribunais Superiores, ao Procurador-Geral da República e aos cidadãos, na forma e nos casos previstos nesta Constituição. (...)

Art. 74. Os Poderes Legislativo, Executivo e Judiciário manterão, de forma integrada, sistema de controle interno com a finalidade de: $(\ldots)$

$\S 2^{\circ}$ Qualquer cidadão, partido político, associação ou sindicato é parte legítima para, na forma da lei, denunciar irregularidades ou ilegalidades perante o Tribunal de Contas da União. (...)

Art. 89. O Conselho da República é órgão superior de consulta do Presidente da República, e dele participam: (...)

VII - seis cidadãos brasileiros natos, com mais de trinta e cinco anos de idade, sendo dois nomeados pelo Presidente da República, dois eleitos pelo Senado Federal e dois eleitos pela Câmara dos Deputados, todos com mandato de três anos, vedada a recondução. (...)

Art. 101. O Supremo Tribunal Federal compõe-se de onze Ministros, escolhidos dentre cidadãos com mais de trinta e cinco e menos 
de sessenta e cinco anos de idade, de notável saber jurídico e reputação ilibada. ${ }^{13}$

Paralelamente, os direitos humanos, destituídos de sua própria essência ontológica, são positivados como expressão simbólica e jurídica do domínio econômico e da hegemonia política de uma determinada classe, isto é, nada mais são do que a tradução legal do princípio dominante da sociedade ${ }^{14}$.

Desse modo, a sociedade contemporânea, organizada sobre as bases do positivismo jurídico, carrega em sua própria essência a antítese entre homem e cidadão, entre excluídos e incluídos, entre marginais e pessoas de bem, apoderando-se assim da figura do homo sacer.

Nessas condições os direitos do homem são contrapostos aos do cidadão, fazendo parte do dispositivo jurídico que simultaneamente legítima e acoberta, inclui e exclui as relações de dominação, sob a capa da igualdade formal de todos perante a Lei, criando-se, assim, um verdadeiro paradoxo.

Assim, a chamada emancipação política do indivíduo nada mais é do que sua própria redução da condição de ser humano, passando-se, assim, do status de ser humano para cidadão do Estado.

Deixando-se aqui o discurso político de lado, necessário se faz uma breve explanação da doutrina de Karl Marx que demonstrou que, desde a aurora da positivação dos direitos humanos, instala-se uma dialética entre homem e cidadão. Para o autor de $O$ Capital, seria necessário atentar para um hiato mal ocultado pelo conectivo "e" nas primeiras declarações de direito das Constituições americana e francesa. Um conectivo que, na verdade, ao mesmo tempo liga e separa homem e cidadão, encobrindo uma diferença - mais que isso -, uma contradição real que tem suas bases em relações sociais de exploração e domínio. Para Marx, a superestrutura jurídico-política do Estado liberal, sobretudo na forma dos modernos Estados nacionais, proveria a moldura institucional exigida pela correspondente configuração da sociedade civil burguesa ${ }^{15}$.

\footnotetext{
${ }^{13}$ Constituição Federal. Disponivel em: http://www.planalto.gov.br/ccivil_03/constituicao/constituicao.htm

14 GIACOIA JUNIOR, Junior. Sobre direitos humanos na era biopolítica. Disponível em:http://www.scielo.br/scielo.php?script=sci_arttext\&pid=S0100-512X2008000200002. Acesso em: 20 de out. de 2018. p. 7.

15 GIACOIA JUNIOR, Junior. Sobre direitos humanos na era biopolítica. Disponível em:http://www.scielo.br/scielo.php?script=sci_arttext\&pid=S0100-512X2008000200002. Acesso em: 20 de out. de 2018. p. 8
} 
Este cenário apenas evidencia o quão problemática é a relação Estado/indivíduo, uma vez que, a qualidade de "cidadão" apenas demonstra a existência juridicamente problemática de pessoas não integradas nacionalmente em uma comunidade política e, portanto, em precária condição no que concerne a proteção legal quanto a seus direitos. Outrossim, este contex to exibe, de maneira evidente, a inaptidão dos Estados soberanos de oferecer proteção legal a todos os indivíduos, sem qualquer tipo de distinção, ou melhor, sem qualquer tipo de discriminação.

Com o intuito de transpor a teoria para o campo prático, basta se ter como exemplo a atípica crise migratória vivenciado pelos países localizados no Oriente Médio e o consequente tratamento que os berços da democracia ocidental - tais como França, Itália, Alemanha - dispensam a esses indivíduos. Esses refugiados, apenas demonstram o hiato entre homem e cidadão, evidenciado-se seu pertencimento a classe de homo sacer contemporâneo.

Não obstante a inalienabilidade dos direitos humanos, tais direitos mostraram-se inexequíveis - mesmo nos países cujas constituições se baseavam neles e se fundamentaram em tais direitos.

Esses indivíduos que não pertencem a nenhuma comunidade política, nem possuem um lugar no mundo no qual possam fincar raízes, tornam manifesta a histórica condição deficitária dos direitos humanos em termos de conteúdo. Os direitos individuais e coletivos, mencionados por todas as declarações de direitos humanos, presumem um direito fundamental, ao qual estão ligados: única e exclusivamente a cidadania ${ }^{16}$.

É neste cenário que se evidencia o quão perverso é este Ente que escolhe um grupo seleto de indivíduos que possuem seus direitos tutelados de outros que nem sequer merecem ser aceitos em território nacional.

Cumpre salientar que, o objetivo deste trabalho não é desvalorizar as conquistas que as Declarações de Direitos Humanos obtiveram, mas sim problematizar a constitucionalização desses direitos pelos Estados soberanos, que na visão do professor Oswaldo Giacoia Junior:

Tudo se passa, portanto, como se, a partir de um certo ponto, todo evento político decisivo tivesse sempre uma dupla face: os espaços, as liberdades e os direitos que os indivíduos adquirem no seu conflito com os poderes centrais simultaneamente preparam, a cada

16 GIACOIA JUNIOR, Junior. Sobre direitos humanos na era biopolítica. Disponível em:http://www.scielo.br/scielo.php?script=sci_arttext\&pid=S0100-512X2008000200002. Acesso em: 20 de out. de 2018. p. 10. 
vez, uma tácita porém crescente inscrição de suas vidas na ordem estatal, oferecendo assim uma nova e mais temível instância ao poder soberano, do qual desejariam liberar-se ${ }^{17}$.

Muito além de qualquer esfacelamento trivial da positivação dos direitos humanos, este trabalho objetiva problematizar o status de admissão de tais direitos como verdadeiras armas de resistência, quando ontologicamente nada mais são senão outro poderoso instituto de dominação e manutenção do status quo, bem como de condenação da natureza humana ontologicamente transformadora.

Tamanha a crise jurídica, política e social em que vivemos que caminhamos a passos largos a uma crise irreversível. Isto porque, o quadro histórico de impotência em que a democracia moderna se encontra - a mesma democracia que muitas das vezes procurou enfrentar o problema do poder soberano - é flagrante ante as mazelas dos Estados soberanos como um todo.

A simbiose entre interesses estatais e ordenamento jurídica não está restrita ao âmbito da Lei Maior dos Estados soberanos. A apropriação do ser humano é mais evidente ainda em legislações penais e demais políticas criminais, já que, nestes campos, o uso da violência pelo Estado nem sequer é mascarada. Ademais, no âmbito penal a figura do homo sacer nunca se mostrou tão manifesta dado o esfacelamento dos direitos humanos quando o indivíduo encontra-se cumprindo uma pena imposta pelo Estado.

\section{A EXPANSÃO DA CRIMINALIDADE E O ESTADO DE EXCEÇÃO QUE SE TORNA REGRA NA DEFESA DAS PESSOAS EM DETRIMENTO DAS NÃO PESSOAS}

Não somente no campo constitucional que o Estado se apropria do indivíduo como ser transformador, mas também em toda sua legislação infraconstitucional e mais precisamente no âmbito penal é que o Estado demonstra flagrantemente suas inconsistências intrínsecas.

Primeiramente, conforme narrado no capítulo 3, tem-se que os Estados soberanos efetivamente constitucionalizam aqueles direitos ditos

\footnotetext{
17 GIACOIA JUNIOR, Junior. Sobre direitos humanos na era biopolítica. Disponível em:http://www.scielo.br/scielo.php?script=sci_arttext\&pid=S0100-512X2008000200002. Acesso em: 20 de out. de 2018. p. 14.
} 
naturais à condição de ser humano. Ocorre que, para exercerem e efetivamente reclamarem tais direitos, os Estados soberanos isolam o indivíduo do cidadão. Esta divisão também é manifesta no âmbito das legislações penais bem como de políticas criminais.

O Direito Penal do cidadão tipifica e sanciona aquelas condutas realizadas pelo indivíduo de maneira fortuita. Assim, na condição de sujeitos vinculados ao Estado, o Direito é muito mais complacente com os seus do que com aqueles indivíduos considerados verdadeiras ameaças às bases fundantes deste Ente político.

Para Gunther Jakobs - idealizador da teoria do Direito Penal do inimigo - o delito praticado por um cidadão nada mais é do que um mero deslize reparável, motivo pelo qual o Estado deve sancioná-lo, mas o faz de maneira protetiva.

Muito diferente é o tratamento dispensado àqueles que o Estado considera como verdadeiros inimigos do sistema, intimidadores do status quo social. A estes, o Estado tem legislações e políticas criminais paralelas. Assim o faz com o intuito de destruir qualquer "semente" apta a quebrar as bases fundantes do Estado. A conduta desses marginais não se mostra adequado e compatível à conduta de cidadãos, a saber nem sequer a de um cidadão-delinquente, mas sim de um verdadeiro inimigo as bases sociais e ao Direito.

Esses inimigos, dado seu distanciamento duradouro do direito, jamais poderão ser considerados como engrenagens da máquina Estatal (são individuos que não produzem e consequentemente em nada acrescentam aos meandros do sistema capitalista). As atividades e as ocupações profissionais de tais indivíduos não ocorrem no âmbito das relações sociais reconhecidas como legítimas, mas naquelas que são, na verdade, a expressão e o expoente da vinculação desses indivíduos a uma organização estruturada que opera à margem do Direito e, portanto, é considerada como uma estrutura paralela às estruturas estatais, oferecendo assim, uma resistência a estas e consequentemente ao regular funcionamento da máquina estatal.

Ademais, ao encontro da Teoria do Direito Penal do inimigo, observe-se outra antinomia das bases que fundamentam e legitimam os estados soberanos. Senão vejamos:

Este estilo de vida imposto pelo Estado aos "cidadãos de bem", qual seja, um estilo de vida consumista, que sobrepõe o econômico ao social, é típico das classes mais altas da sociedade, pois estas possuem recur- 
sos capazes de alimentar essas falsas necessidades. Entretanto, quando escoado para as classes mais baixas, tendem a causar desastres irreversíveis, uma vez que, em razão da falta de recurso para acompanhar esse estilo de vida frenético, os indivíduos das classes mais baixas se inclinam a desenvolver comportamentos criminológicos, tanto para suprir tais necessidades como para tapar o buraco existencial causado por essas falsas carências. Vive-se, assim, o seguinte dilema: "você é aquilo que você tem".

Aqui se faz necessário discorrer sobre os ordenamentos jurídicopenais como um todo, com ênfase, é claro, no sistema penal brasileiro e suas políticas públicas.

Conforme descrito supra, ao estimular o consumo desenfreado, aqueles que não possuem recursos para alimentar o sistema capitalista são os novos excluídos, marginalizados, abandonados, verdadeiros homo sacers contemporâneos, que muitas das vezes recorrem a criminalidade para sustentar aquela necessidade criado pelo próprio Estado para sua manutenção.

Assim sendo, analisando profundamente as causas dos altos índices de criminalidade, chega-se à conclusão que aquele ente político que pune de maneira excessiva, pune por circunstâncias criadas pelo próprio ente, captando-se assim, novamente, aquele Estado fortemente marcado por antinomias.

Neste cenário, ao praticar condutas consideradas como infrações penais, esses marginais - interessante notar o conceito da palavra que significa estar à margem da sociedade, ou seja, não se adequa aos parâmetros centrais - são considerados verdadeiros ruptores da ordem e do status almejados pelo Estado e são de pronto jogados nas masmorras denominadas legalmente de penitenciárias. Figurando como "hospedes" das penitenciárias, lá são esquecidos, pois não é interessante para o Estado cuidar daqueles indivíduos que agem contrariamente aos valores apregoados pelo Estado e, ainda que indiretamente, representam verdadeira ruptura as bases fundantes deste ente político.

Para Cezar Roberto Bittencourt:

Como se percebe, há um grande questionamento em torno da pena privativa de liberdade, e se tem dito reiteradamente que o problema da prisão é a própria prisão. Aqui, como em outros países, a prisão corrompe, avilta, desmoraliza, denigre e embrutece a pessoa do 
condenado (...). Sabe-se hoje que a prisão reforça os valores negativos do condenado. O réu tem um código de valores distintos daquele da sociedade ${ }^{18}$.

Assim o faz tendo em vista que, o poder individual - aquele poder inerente à condição de ser humano e principal responsável por transformações sociais - é visto pelo Estado como um perigo de subversão da ordem estabelecida. Aparentemente poderia-se sustentar que os fins individuais entram em choque com os fins do Direito na medida em que este representa os fins do próprio Estado soberano.

Trata-se da possibilidade de o poder, quando não cai sob a alçada do respectivo direito, o ameaçar, não pelos fins que possa ter em vista, mas pela sua simples existência fora do âmbito do direito. Por conseguinte, o único objetivo almejado pelo direito é se fortalecer e se manter, conservando o poder e o status quo e não aspirar fins justos como proclama suas mais românticas teorias. Assim, a crítica ao direito como um todo é imprescindível.

Um exemplo prático de sobreposição do interesse do Estado por meio do Direito sobre o indivíduo, que Walter Benjamin, em seu livro $O$ anjo da história traz, é a pena de morte, já que, “[...] na aplicação do poder sobre a vida e a morte, mais do que em qualquer outra aplicação da lei, é o próprio direito que se fortalece ${ }^{19}$ ".

Paralelamente à construção de um complexo ordenamento jurídico, para garantir o poder estatal sobre todos, criou-se, dentre outros instrumentos, um que chama especial atenção, qual seja, a polícia, que acima de tudo exerce-se mais cegamente sobre áreas vulneráveis e pessoas previamente selecionadas contra as quais o Estado não estaria protegido tão somente pelas leis, certificando, assim, a supremacia de seus próprios interesses.

Dessarte, é notório o poder que os ordenamentos jurídicos exercem para uniformização e coesão das pessoas, pois "é com as proibições que a indústria cultural fixa positivamente sua própria linguagem com sua sintaxe e seu vocabulário" 20 . É por meio de proibições de determinados comportamento que se fixa uma linha tênue daquilo que é bom aos olhos

\footnotetext{
${ }^{18}$ BITENCOURT, Cezar Roberto. Tratado de direito Penal, Parte Geral 1. $21^{\mathrm{a}}$ ed. rev. e atual. São Paulo: Saraiva, 2015. p. 221.

${ }^{19}$ BENJAMIN, Walter. O Anjo da História. Belo Horizonte: Autêntica Editora, 2013. p. 93.

${ }^{20}$ ADORNO, Theodor W.; HORKHEIMER, Max. Dialética do Esclarecimento. Editora Zahar. 1985. p. 120.
} 
da classe dominante para aquilo que poderá provocar sua queda. Muito melhor aos olhos deles que milhões sejam encarcerados e esquecidos, do que ter seu poder e sua dominação questionados.

Assim agindo, essa sociedade cria um ciclo vicioso, difícil de ser rompido, uma vez que, ao priorizar o capital, aqueles que não o detém são previamente marginalizados pois não se adequam às vestes dessa cultura. A única opção dessas pessoas previamente marginalizados é acreditarem no que os detentores do poder dizem a seu respeito, e se tornarem, de fato, verdadeiros marginais.

Os detentores do poder jamais poderão eximir-se do fato de que este poder individual, considerado um grande inimigo da "ordem" estabelecida, é um poder inerentemente humano, que está associado à própria ontologia de ser humano. Assim sendo, este mesmo Estado, com o intuito de enfraquecer este poder de transformação, retira a humanidade da pessoa e tende a transformá-la em mero corpus vivendi, sendo um ser passível e previsível, um ser ignorante e influenciado pela demagogia, destituído de vontade própria, um verdadeiro animal domesticável.

Logo, se por qualquer motivo uma pessoa representar uma ameaça para o Estado, prontamente este Estado pode decretar a perda total ou parcial de determinados direitos.

Nesta senda Giorgio Agamben, em seu livro "homo sacer: o poder soberano e a vida nua I", constrói toda sua tese. Para o autor, homo sacer é uma figura do Direito Romano arcaico que era dotado de uma sacralidade, ou seja, era uma figura predestinada que não poderia ser sacrificada pois já pertencia aos deuses e, ao mesmo, também era um ser matável que qualquer um poderia tirar a vida sem assim cometer homicídio. A contradição é ainda mais acentuada pela circunstância de que aquele que qualquer um podia matar imponentemente, não devia, porém, ser levado à morte nas formas sancionadas pelo rito, ou seja, ao mesmo tempo que a figura era sagrada também era profana pois não havia uma clara diferença entre ambos ${ }^{21}$.

Para Agamben, é a figura do homo sacer que sustenta o poder soberano e condiciona todas as outras normas, pois é disso que o Estado precisa, de um ser previsível, que ao aparentar ser o fim de toda uma estrutura, inclusive jurídico, é simplesmente um ser descartável, substituível

\footnotetext{
${ }^{21}$ AGAMBEN, Giorgio. Homo Sacer: O Poder Soberano e a Vida Nua I. 2. ed. Belo Horizonte: Ufmg, 2014.
} 
quando se deseja, mera engrenagem para a máquina estatal. Senão vejamos:

\begin{abstract}
O que temos hoje diante dos olhos é, de fato, uma vida exposta como tal a uma violência sem precedentes, mais precisamente nas formas mais profanas e banais. O nosso tempo é aquele em que um week-end de feriado produz mais vítimas nas auto-estradas da Europa do que uma campanha bélica; mas falar, a propósito disto, de uma sacralidade do garde-rail é, obviamente, apenas uma definição antifrástica ${ }^{22}$.
\end{abstract}

Insta ressaltar que, tamanhas são as antinomias sociais, dentre os quais o conflito entre o real e o aparente, que Giorgio Agambem afirma que aquele Estado de normalidade que deveria ser a "regra do jogo", não o é. Vive-se em uma sociedade que o Estado de exceção/anormal é a regra. Isto porque, para Agambem, o núcleo da soberania, ou seja, seu fundamento, não é a normalidade, mas sim o estado de exceção - há uma superioridade da exceção. "Uma das teses da presente investigação é a de que o próprio estado de exceção, como estrutura política fundamental, em nosso tempo, emerge sempre mais ao primeiro plano e tende, por fim, a tornar-se regra". ${ }^{23}$

Segundo o professor Gerson Rosa, é com a figura do homo sacer que se torna notório o fortalecimento da política "da vida" e não "para vida". É, pois, uma política como recurso funcional para a eficiência institucional, onde a vida se torna meio da política entendida como gestão, que se torna uma fim. Uma absurda inversão de valores. "O homo sacer não só mostra a fragilidade da vida humana abandonada pelo direito, mas também, e mais importante, revela a existência de uma vontade soberana capaz de suspender a ordem e o direito" 24 .

É neste cenário que a institucionalização da violência como princípio do direito representa a inclusão da vida na esfera de controle do poder soberano. Assim também se constata que a mesma violência que funda o Direito é a violência que o conserva, afastando assim qualquer ameaça a suas estruturas. Há um liame inerente entre direito e violência e direito e

\footnotetext{
${ }^{22}$ AGAMBEN, Giorgio. Homo Sacer: O Poder Soberano e a Vida Nua I. 2. ed. Belo Horizonte: Ufmg, 2014. p.121.

${ }^{23}$ AGAMBEN, Giorgio. Homo Sacer: O Poder Soberano e a Vida Nua I. 2. ed. Belo Horizonte: Ufmg, 2014. p.27.

${ }^{24}$ ROSA, Gerson Faustino. O estado de exceção na era bio-política: O jogo da legitimação pelo direito. disponivelem:http://www.esmarn.tjrn.jus.br/revistas/index.php/revista_direito_e_liberdade/announcement/view/50. Acesso: 2018.
} 
poder, liame este que caracteriza a experiência ocidental de instrumentalização da força para sistematização do direito.

\footnotetext{
O que o direito não pode tolerar de modo algum e sente como uma ameaça contra a qual é impossível transigir é a exigência de uma violência fora do direito; não porque os fins de tal violência sejam incompatíveis com o direito, mas pelo simples fato de sua existência fora do direito ${ }^{25}$.
}

Entre os paradoxos e antinomias da técnica social, aqui caracterizada como ordem coercitiva, encontra-se também o fato de o seu instrumento específico, o ato coercitivo de sanção, ser exatamente do mesmo tipo que o ato que ele busca prevenir nas relações dos indivíduos: o delito. $\mathrm{O}$ fato de que a sanção contra uma conduta socialmente danosa é, ela própria, uma conduta similar, pois o que deve ser obtido através da ameaça de perda de vida, saúde, liberdade ou propriedade é precisamente que os homens, em suas relações mútuas, se abstenham de privar um ao outro de vida, saúde, liberdade ou propriedade. "A força é empregada para prevenir o emprego da força na sociedade" ${ }^{26}$. Trata-se, de fato, de outra antinomia que legitima os estados soberanos.

Assim, o maior inimigo do homem é o próprio homem, materializado na figura do ser vingativo, daquele indivíduo que pune de maneira exorbitante sua própria espécie para saciar sua "sede de justiça", para tapar o buraco de suas aflições existenciais. Para tanto, este ser punitivo se agarra a falsas bases e a ilusórios argumentos - usando a própria religião de maneira distorcida pois muitas das vezes percebe-se uma interiorização e espiritualização da crueldade para sentirem-se bem consigo mesmos e não cair nas profundezas da desolação humana. Para tanto, contam com total apoio do ordenamento jurídico.

Ora, não há nada mais desumano do que este sistema punitivista sustentado por um incoerente ordenamento jurídico que não está preocupado em recuperar seu semelhante, mas sim puni-lo e condená-lo de maneira perpétua. Um grande exemplo de perpetuação da pena são os antecedentes criminais que transforma o indivíduo em eterno "bandido" aos olhos da sociedade.

\footnotetext{
25 GIACOIA JUNIOR, Junior. Sobre direitos humanos na era biopolítica. Disponível em:http://www.scielo.br/scielo.php?script=sci_arttext\&pid=S0100-512X2008000200002. Acesso em: 20 de out. de 2018.

26 GIACOIA JUNIOR, Junior. Sobre direitos humanos na era biopolítica. Disponível em:http://www.scielo.br/scielo.php?script=sci_arttext\&pid=S0100-512X2008000200002. Acesso em: 20 de out. de 2018.
} 
"Nesta senda, a vida humana é vista pelo Direito sempre com a ameaça potencial de ser decretada a vida nua em razão da condição perecível de ser humano"27.

Os campos de concentração nazistas eram vistos pelos cidadãos alemães com a mesma normalidade e necessidade que atualmente vemos as penitenciárias. Os judeus eram vistos pelos cidadãos alemães com a mesma aversão que atualmente vemos os "bandidos". As atrocidades praticadas por Hitler eram vistas pelos cidadãos alemães com certa normalidade, da mesma maneira que vemos com certa normalidade aquelas atrocidades praticadas pelo Estado contra os "marginais".

Segundo Gerson Rosa:

\begin{abstract}
No atual contexto de globalização, isto é, no atual mundo regido por uma única ordem econômica, política, policial e militar, num mundo sem fronteiras, surgem figuras novas que acabam ficando à margem do direito e da sociedade, reatualizando os campos de concentração da Alemanha Nazista. Existem hoje inúmeros campos de refugiados, "campos de concentração" onde estão suspeitos de terrorismo. Há uma soberania mundial que atua suspendendo uma ordem jurídica internacional, criando não sujeitos, extirpados de sua cidadania. O Estado de Exceção se apresenta como a forma legal daquilo que não pode ter forma legal ${ }^{28}$.
\end{abstract}

Eis novamente o cenário descrito nas páginas iniciais deste trabalho, qual seja, que o poder que sustenta e mantém o direito, no decorrer do tempo, acaba enfraquecendo indiretamente o poder instituinte do direito representado por ele, através da opressão dos antigos inimigos. É este ciclo vicioso que observamos em todo auge e posterior queda de grandes civilizações.

Aqui se faz extremamente necessário ressaltar que, este cenário de contradições contextualizado supra, não é limitado a um ou outro Estado especificamente, mas sim a sociedades contemporâneas como um todo, independente de sua forma de Estado, forma de governo ou suas ideologias. Quer o homem viva sob um regime totalitário quer sob um regime democrático, o exercício do poder político torna-o sujeito a ser despido de sua

\footnotetext{
${ }^{27}$ ROSA, Gerson Faustino. O estado de exceção na era bio-política: O jogo da legitimação pelo direito. disponivelem:http://www.esmarn.tjrn.jus.br/revistas/index.php/revista_direito_e_liberdade/announcement/view/50. Acesso: 2018.

${ }^{28}$ ROSA, Gerson Faustino. O estado de exceção na era bio-política: O jogo da legitimação pelo direito. disponivelem:http://www.esmarn.tjrn.jus.br/revistas/index.php/revista_direito_e_liberdade/announcement/view/50. Acesso: 2018.
} 
humanidade. Basta observar o tratamento dispensados àqueles considerados "terroristas" pelos Estados Unidos da América que, dentre outros flagelos, são encarcerados em uma ilha fora dos alcances das proteções legais oferecidas em território nacional, isto é, Guantánamo; bem como, mais recentemente, ao tratamento auferido pelas maiores potências europeias aos refugiados do Oriente Médio.

De forma conclusiva, eis o contexto em que vivemos: um Estado controlado por determinada classe política, que confunde sua própria vontade com a vontade do Estado soberano, fundado por inúmeras leis que só se preocupam em legitimá-lo e eternizá-lo, retirando poderes de qualquer um que ameace a sua existência enquanto tal e utilizando os indivíduos como meios e objetos para seu plano de poder.

Assim, na crença de uma sociedade civilizada, vive-se em uma sociedade animalesca, marcada por brutalidades nunca vistas antes, sociedade esta totalmente imprevisível, que diante de seu declínio moral, sua queda será inevitável.

\section{6 A VIDA NUA E O ESTADO SOBERANO: UMA ANÁLISE
CRÍTICA DA NECESSIDADE SUBSTANCIAL DE
CONSTRUÇÃO DO SER}

No atual cenário, imprescindível se faz a construção de uma breve síntese da importância que o indivíduo pensante e crítico possui para contextualizar mudanças e transformações sociais com o fito de desmantelar todo fundamento em que as sociedades atualmente se sustentam e consequentemente trilhar um caminho verdadeiramente civilizatório, em que o ser humano, não só aparentemente, mas fatidicamente, é a base e o fím para todas as ciências. Para tanto, é necessário retomar aquele dito "poder individual" que tanto assusta o Estado moderno e reformular profundamente todo sistema jurídico que fundamente a apropriação da vida pelos estados soberanos.

No prefácio da obra "Dialética do esclarecimento", Theodor W. Adorno e Max Horkheimer, captando a antítese social em que nos encontramos, chegaram a afirmar que "O que nos propusemos era, de fato, nada menos do que descobrir por que a humanidade, em vez de entrar em um 
estado verdadeiramente humano, está se afundando em uma nova espécie de barbárie". ${ }^{29}$

Insta ressaltar que o pensamento crítico e o termo "esclarecimento" caminham juntos. Segundo Theodor W. Adorno e Max Horkheimer o esclarecimento, que outrora era a ponta da lança da conquista das liberdades, foi "auto destruído", uma vez que, os antigos porta vozes dessa teoria, agora, na condição de detentores do poder, liquidam a teoria que os ajudou a encontrar "um lugar ao sol". Liquidam no sentido de atribuírem uma acepção diversa do verdadeiro significado da palavra, que ao ser usado para conquista de liberdades, agora serve única e exclusivamente para seus interesses dominadores.

Ao tachar de complicações obscuras o pensamento que se aplica negativamente aos fatos, bem como às formas de pensar dominantes, e ao colocar um tabu sobre ele, essa cultura mantém o espírito sob o domínio da mais profunda cegueira.

Assim, conforme dito acima, a mesma razão que foi utilizado para livrar os homens do medo, para alçá-los a posição de senhores de si mesmo e do próprio destino, livrando o mundo de todos os mitos, substituindo a imaginação pelo saber - pois a superioridade do homem está no saber, saber este que não conhece nenhuma barreira - agora restringi-se a meras ilações "racionais" e calculistas. Agindo assim, apropriaram para si o termo "esclarecimento" atribuindo-lhe outro significado, muito diferente daquele que sempre acompanhou a palavra.

\begin{abstract}
Neste diapasão, toda a pretensão do conhecimento é abandonada. Ela não consiste no mero perceber, classificar e calcular, mas precisamente na negação determinante de cada dado imediato. Ora, ao invés disso, o formalismo matemático, cujo instrumento é o número, a figura mais abstrata do imediato, mantém o pensamento firmemente preso à mera imediatidade. $\mathrm{O}$ factual tem a última palavra, o conhecimento restringe-se à sua repetição, o pensamento transforma-se na mera tautologia, desse modo o esclarecimento regride à dominação. ${ }^{30}$
\end{abstract}

Para manter o status quo da sociedade, os detentores do poder, como explicitado ao longo do trabalho, necessitam abafar ao máximo o

\footnotetext{
${ }^{29}$ ADORNO, Theodor W.; HORKHEIMER, Max. Dialética do Esclarecimento. Editora Zahar. 1985. p. 8.

${ }^{30}$ ADORNO, Theodor W.; HORKHEIMER, Max. Dialética do Esclarecimento. Editora Zahar. 1985. p. 57.
} 
sentimento crítico dos dominados, e para isso eles devem preencher a cabeça destes com diversões artificiais, criando assim o que os autores chamam de uma verdadeira "indústria da diversão".

Assim já preconizava Friedrich Nietzsche em seu livro "Assim falava Zarastura" que "Para eles, o que modera e domestica é virtude; assim fizeram do lobo um cão e do próprio homem, o melhor animal doméstico do homem" ${ }^{31}$.

As consequências de repugnantes práticas visam a metamorfose do ser humano em ser fungível, onde todos são substituídos, não existindo mais peculiaridades nem especialidade, fulminando do sujeito pensante o pensamento crítico. Para tanto, utilizam-se também de instituições que formam o indivíduo tais como escola e família, para, desde a infância, implantarem a ideia de viver para ter e não de viver para ser.

Nesta senda, para ruir com o poder disciplinar que tanto auxilia na manutenção do status quo, talvez seja necessário se buscar um poder não disciplinar, uma vez que não devemos ir na direção do "antigo Direito", caso contrário estaríamos fadados ao mesmo insucesso que aflige suas bases.

Como pensar um novo Direito, para fazer face às urgências que nos acometem, e pelo menos acenar na direção de um plano em que poderíamos evitar a captura da vida nua nas insidiosas armadilhas das modalidades atuais de poder soberano?

Ademais, a experiência é farta em nos demonstrar a inocuidade de tão somente se indignar ante ao precipício social em que nos encontramos. É preciso materializar essas críticas e suscitar a criação de um direito desvinculado do poder soberano, um Direito não estatal, unicamente vinculado ao indivíduo enquanto ser e não enquanto cidadão ${ }^{32}$.

Um dia, a humanidade brincará com o Direito, como as crianças brincam com os objetos fora de uso, não para devolvê-los a seu uso canônico e, sim, para libertá-los definitivamente dele. O que se encontra depois do direito não é um valor de uso mais próprio e original e que precederia o direito, mas um uso novo, que só nasce

\footnotetext{
${ }^{31}$ NIETZSCHE, Friedrich. Assim Falava Zarastrura. $3^{\text {a }}$ Ed. Petrópolis/RJ: Vozes, 2014. p. 219.

32 GIACOIA JUNIOR, Junior. Sobre direitos humanos na era biopolítica. Disponível em:http://www.scielo.br/scielo.php?script=sci_arttext\&pid=S0100-512X2008000200002. Acesso em: 20 de out. de 2018.
} 
depois dele. Também o uso, que se contaminou com o direito, deve ser libertado de seu próprio valor. ${ }^{33}$

Não obstante essa visão pessimista acerca da humanidade e do dito esclarecimento, tem-se que o ser não está perdido, uma vez que, é da natureza do homem carregar dentro de si certos questionamentos, certas inquietações. Não obstante uma determinada classe se incline a fulminar esta potencialidade, ela ainda está ali, presente, conclamando por uma oportunidade para novamente renovar a sociedade. O esclarecimento de fato é tão destrutivo como acusam seus inimigos. Ocorre que ele só irá se reencontrar quando renunciarmos ao último acordo com esses inimigos e tivermos a ousadia de superar o falso absoluto que é o princípio da dominação cega.

\section{CONCLUSÃo}

No decorrer deste trabalho, procurou-se fazer uma análise crítica da sociedade atual de forma mais imparcial possível, tendo em vista que, no decorrer da história observou-se que, para que uma nova ordem possa se estabelecer, o primeiro passo é construir um pensamento crítico voltado para os fundamentos e as bases que sustentam a ordem até então estabelecida. Só então será possível a construção de uma nova sociedade, pautandose nessas críticas, para que os mesmos erros não sejam novamente cometidos.

Entretanto verificou-se também que, a partir do momento em que é instituída uma nova ordem jurídica, aparentemente mais louvável do que a anterior, logo seu objetivo, assim como a anterior, é apenas se manter no poder, mesmo que para isso tenha que abandonar ideais iniciais "legitimadores".

Um olhar que se concentre apenas no que está mais próximo aperceber-se-á, quando muito, de uma oscilação dialética nas formas assumidas pelo poder enquanto instituinte do Direito ou tendente a manter esse Direito. A lei dessa oscilação assenta-se no fato de todo poder tendente a manter o direito, no decorrer do tempo, acabar por enfraquecer indiretamente o direito instituinte do poder nele representado, através da opressão

\footnotetext{
${ }^{33}$ Ibidem.
} 
dos poderes contrários e a consequente instrumentalização do ser humano e manipulação de sua vida pelo Estado.

Essa situação mantém-se até que novos poderes, ou os anteriormente oprimidos, vençam a ordem instituinte do direito, fundando com isso um novo Direito predestinado à decadência. Eis a enorme crise existencial em que vivemos quando nos encontramos inseridos em uma sociedade política, eis o ciclo que devemos romper antes que o caos tome conta da humanidade - se já não o tomou.

Com relação ao "problema da criminalidade", este tem gerado uma forte demanda de políticas criminais duras com o recrudescimento das leis e ampliação de tipos penais, muitas vezes desprovidos de seu exclusivo objeto de proteção, qual seja o bem jurídico-penal. Paralelamente a isso, a necessidade de proteção dos bens jurídicos transindividuais, faz emergir, dia a dia, a preocupação de proteção da sociedade, induzindo-nos a admitir quaisquer meios para alcançar tal fim, esquecendo-se da pessoa, que é o centro e o fim do Estado ${ }^{34}$.

Nesta senda, dada sua complexidade, o fenômeno criminal merece especial atenção, seja sob uma perspectiva jurídica, seja sob uma perspectiva política e sociológica do comportamento humano, devendo-se desconstruir, de pronto, a falsa tese de que punindo, melhora. $\mathrm{O}$ intuito de punir jamais pode ser a premissa que fundamenta o Direito Penal.

O que de fato deve-se ter em mente é que sempre houve e sempre haverá uma distinção clara entre estados soberanos e ordenamentos que positivam direitos. A despeito da abrupta imersão do direito nas bases que fundam os estados, o direito sempre estará além do estado, limitando-o e garantindo sobretudo a proteção dos indivíduos na qualidade de seres humanos, colocando-os como finalidade dos Estados.

Nesse diapasão, não se pode tergiversar sobre os direitos fundamentais conquistados, a duras penas, pela humanidade, a pretexto de "proteção social", ou ainda, de se buscar qualquer fim alheio à proteção do indivíduo. "O intuito de punir não pode permear a criação e aplicação do Direito Penal. Em primeiro lugar, deve se assegurar os direitos e garantias fundamentais, e não a efetividade e aplicação da lei penal" ${ }^{\text {"35 }}$.

\footnotetext{
${ }^{34}$ ROSA, Gerson Faustino. O estado de exceção na era bio-política: O jogo da legitimação pelo direito. disponivelem:http://www.esmarn.tjrn.jus.br/revistas/index.php/revista_direito_e_liberdade/announcement/view/50. Acesso: 2018.

${ }^{35}$ ROSA, Gerson Faustino. O estado de exceção na era bio-política: O jogo da legitimação pelo direito. disponivelem:http://www.esmarn.tjrn.jus.br/revistas/index.php/revista_direito_e_liberdade/announcement/view/50. Acesso: 2018.
} 


\section{REFERÊNCIAS}

AGAMBEN, Giorgio. Homo Sacer: O Poder Soberano e a Vida Nua I. 2. ed. Belo Horizonte: Ufmg, 2014. $183 \mathrm{p}$.

ANDREATTA FILHO, D. R. ; ZENNI, Alessandro Severino Valler . A (re)construção da dignidade humana e do direito em perspectiva interdisciplinar na contemporaneidade. São Paulo-SP:

A Espiritualidade na Vida Contemporânea.. Realização de Café Filosófico; Jurandir Freire Costa. S.i.: Tv Cultura, 2014. (37 min.), color.

BAUMAN, Zygmunt. Modernidade Liquida. Rio de Janeiro: Ed. Zahar, 2001.

BENJAMIN, Walter. O Anjo da História. Belo Horizonte: Autêntica Editora, 2013.

BITENCOURT, Cezar Roberto. Tratado de direito Penal, Parte Geral 1. 21 $1^{\mathrm{a}}$ ed. rev. e atual. São Paulo: Saraiva, 2015.

CONPEDI, 2009. v. 1. KAFKA, Franz. A Metamorfose. 2. ed. São Paulo: Companhia das Letras, 2000. 102 p. KAFKA, Franz. O Processo. São Paulo: L\&PM, 1925. 144 p.

GIACOIA JUNIOR, Junior. Sobre direitos humanos na era biopolítica. Disponível em:http://www.scielo.br/scielo.php?script=sci_arttext\&pid=S0100-512X2008000200002. Acesso em: 20 de out. de 2018.

LYRA FILHO, Roberto. O que é direito. 21. ed. São Paulo: Brasiliense, 2012. 104 p

MARTIN, Luis Gracia. O horizonte do finalismo e o direito penal do inimigo. 10. ed. São Paulo: RT, 2007.

MENDONÇA, Jacy de Souza. O Curso de Filosofia do direito do Professor Armando Câmara. Porto Alegre: Sergio Antonio Fabris Editor, 1999. 263 p.

NIETZSCHE, Friedrich. Assim Falava Zarastrura. 3ª Ed. Petrópolis/RJ: Vozes, 2014.

ROSA, Gerson Faustino. O estado de exceção na era bio-política: O jogo da legitimação pelo direito

ZENNI, Alessandro Severino Valler ; MESQUITA, C. . Crítica à Justiça da Atualidade: por um resgate histórico da Filosofia do direito. Revista Quaestio Iuris Universidade Estadual do Rio de Janeiro , v. 7, p. 13, 2014.

ZENNI, Alessandro Severino Valler ; FELIX, D. V. . Educação para construção de dignidade: tarefa eminente do direito. Revista Jurídica CESUMAR. Mestrado , v. 11, p. 169-192, 2011.

ZENNI, Alessandro Severino Valler ; SILVA, E. L. . Algumas considerações sobre o princípio da dignidade da pessoa humana. Revista Jurídica CESUMAR. Mestrado , v. 9, p. 201-222, 2009. 
ZENNI, Alessandro Severino Valler ; O agir comunicativo em Habermas e a nova retórica de Perelman. Revista Jurídica CESUMAR. Mestrado , v. 7, p. 461-470, 2007.

ZENNI, Alessandro Severino Valler ; direitos e poder na filosofia pós-moderna. Revista Jurídica CESUMAR. Mestrado, v. 5, p. 13-30, 2005.

ZENNI, Alessandro Severino Valler ; O retorno da metafísica como condição para concretização da dignidade da pessoa humana. Revista Jurídica CESUMAR. Mestrado , v. 4, p. 05-14, 2004.

ZENNI, Alessandro Severino Valler; OLIVEIRA, C. R. T. . A pessoa como causa e fim de todo direito. In: Pietro de Jesús Lora Alarcón. (Org.). Filosofia do direito III. 1ed.Florianópolis-SC: Boiteux, 2014 , v. 1, p. 39-54.

ZENNI, Alessandro Severino Valler ; A crise do direito liberal na pós-modernidade. 1. ed. Porto Alegre: Sérgio Antonio Fabris, 2006. v. 1. 183p . 